\title{
Aquatic Biodiversity --- A Neglected Story
}

\author{
Chattopadhyay $\mathrm{NR}^{1^{*}}$ and Sandipta Shee ${ }^{2}$ \\ ${ }^{1}$ Department of Biotechnology, Government of India \\ ${ }^{2}$ Department of Aquaculture Management Technology, Vidyasagar University, Midnapore, West Bengal, India
}

Received: February 04, 2018; Accepted: February 19, 2018; Published: February 28, 2018

*Corresponding author: Chattopadhyay NR, Department of Biotechnology, Government of India, Tel: +7003627768; E-mail: nrchatterjee40@ gmail.com

\section{Abstract}

A comparison of conservation measures directed towards terrestrial and aquatic environment revealed the magnitude of loss yielded by this sector only due to want of less attention from conservation biologists. For a considerable time frame, except marine mammals, the activities relating to preservation of aquatic biodiversity seem to be lagging far behind than that of the terrestrial component. Now at this space when a considerable number fishes and other important aquatic animals has disappeared and with the realization that fish is the only feed resources harvested from natural population, a growing concern has come up for proper management of this unique natural resources.
\end{abstract}

Key words: Conservation; aquatic biodiversity; proper management; natural resources;

\section{Introduction}

The scientific approach to protect aquatic biodiversity, for practical reason, has been initiated over the last two decades, A major cause of delay in implementing adequate conservation measures may be out of ignorance and indifference towards the implications of continued loose of aquatic biodiversity. Added to it, the conflict between conservation and commercial interests play negatively against any effective action. There are, however, several characteristics of the aquatic environment that present fishery managers, decision makers and conservation biologists with a unique set of problems that require special attention. These differing characteristics may have contributed to the general lag of conservation efforts directed towards the aquatic environment. Along with these intentional and unintentional release in both marine and freshwater ecosystem and their disruptive effects has already been established worldwide. This include partial and complete replacement and extinction of local populations, spread of disease and compounded by many other negative interactions affects the genetic integrity through hybridization. As of today, it is really hard to assess the magnitude of damage and to formulate suitable measure to rebound the genetic consequences on aquatic biodiversity (Allendrop and Leary, 1988).

\section{Specialty of aquatic conservation}

The distinctness of aquatic environment with regard to its protection of biodiversity is based on numerous attributes and has been described previously by numbers authors (Allendrop, et al. [1]). Some of the major characteristics to aquatic conservation are as follows: -

a) National Sovereignty- The universal ownership of vast marine areas creates a problem about who to manage and what part, not encountered in terrestrial sector. General consortium, involving al the participatory countries, need to be developed for conservation of many vulnerable species.

b) Hugeness of biodiversity-As pointed out by Ray, [10] aquatic diversity almost doubles than that of land. The robustness, quantity of diversified species and depth offers a hindrance for proper management program.

c) Environmental continuity-Inherent problems related to oceanic complexity multi-ownership is aggravated by the continuity of ocean environment and this continuity led to create an epidomicity of a local problem at a global scale.

d) Anthropomorphism- The aquatic animals, due to their unacceptable morphometric characteristics like wet, cold, slimy are unable to attract emotions of overt physical affection and are devoid of anthropomorphic feelings compared to terrestrial counterpart.

e) Invisibility- Again, the aquatic living entities, as they subsist under water, poses a difficulty to observe study and enumerate. These limitations restrict the capability to detect the mere presence and absence of a particular species and population in a specific habitat.

f) Harvest - Being a major food resource for human being its large-scale harvest from wild accompanied by invisibility creates a problem for assessment and implementation of specific conservation program of the several approaches non-selective harvest otherwise known as "mixed fishery" creates a unique constraint in initiating conservation program for aquatic marine animals. These non-selective approaches for a target species is not only destructive but lead to the unfathomable loss and extinction of too many important fisheries and other group of aquatic inhabitants like dolphins.

g) Genetics- Due to characteristics phenotype- genotype relationship, large phenotypic variations, higher susceptibility to environmental variations are some of the hindrance that stand against natural conservation measures for aquatic organisms. 
h) Hybridization- Compared to other vertebrates, hybridization in fish is not only easy but produce viable and fertile offspring when cross extends up to generic and even higher level. Genetic flexibility, identical chromosome number, isozyme gene expression and conserved nature of marker are some of the criteria that make hybridization easy. There are several reports of hybridization in nature among the most prized groups of fishes like Rohu, Catla and Mrigal-indigenous major carps of India and are considered as prized fishes due to high market demand and excellent palatability. In Indian hatcheries hybridization is undertaken both inadvertently through mixed spawning and advertantly through stripping, for sake of convenience and profit, thus hybridization extends up to generic level and even with exotic species. Resulting in quality deterioration of fish seed. Hybridization through genetic introgression acts as a negative counterpart in conservation approach to aquatic biodiversity (Hinder, et al. [4]; Waples 1991a).

\section{Relative biasness in conservation efforts}

Since 1980, various world bodies like FAO, UNEP elucidated a strong need for conservation of aquatic biodiversity and expressed concern for existing a pronounced lag in conservation efforts towards aquatic biodiversity. Recent data from Red Data Book (IUCN, 1990) reflects the least concern for aquatic biodiversity where fish is enlisted as the less threatened group among vertebrates, when the actual picture is just reverse. Again, roughly one third of the listed fishes represent one or two species, more reflection on the geographical distribution of fishery biologists and proportionate consideration of fishes as "endangered" or vulnerable i.e. next to extinct reflects the mere negligence to aquatic sector.

Another lucid example of neglect in conservation efforts is the comparison of publication profile between terrestrial and aquatic conservation IUCN 1997. Although data (IUCN Red data Book, [6]) indicates that number of publications concerning aquatic conservation in the last 50 years is more than double than that of terrestrial one, the proportionate conservation efforts initiated is less than half than terrestrial one. Added to this the generally increasing awareness of conservation issues, reflected in terms of publications, indicate a trend of least concern over aquatic sectors.

In the back drop of such neglect, it is encouraging to notice that a good number of journals, specifically dealing with the aquatic conservation have come up in the last 30 years. Along with this, specialist body concerning aquatic conservation, have been added to various world body like FAO, IUCN etc.

\section{Genetic considerations of aquatic conservation}

It is known and an established fact that genetic variation within species i.e. between populations as well as between individuals within population is essential for their potential to survive, and for successfully evolving in response to both shortterm and long-term environmental changes. In spite of this realization, most contemporary conservation efforts are directed towards species level and above. Considering the same proper emphasis should be given for the documentations of intra specific variation along with species and higher taxonomical genetic variation. Extinction, hybridization and loss of genetic variation within populations represent the three major categories of threat to genetic diversity within species. These categories reflect the hierarchial organization of intra specific genetic diversity i.e. between genes within individuals, among individuals within populations, between population within geographical regions, among regions within continents or oceans and so on. Genetic diversity between populations (or at other levels in the hierarchy) is reduced when a genetically distinct population ceases to exist or when its integrity is compromised through hybridization. The threats to intra specific genetic diversity are not merely abstraction as has been supported by several literatures (Ross, [13]; Aching, 1990; Phillip, [8]; Ricker, [12]; Andrews, 1990; Waples, 1991a).

\section{Threats to intra specific genetic diversity}

The three major categories that possess threats to intra specific genetic diversity include extinction, hybridization and loss of genetic variation within population (Ryman, [14]). This concept reflects three phases of intra specific genetic diversity such as between genes within individuals, among individuals within population, between population within geographic regions as well as among regions within continents and oceans. Genetic diversity between populations or even at other hierarchal levels is reduced or ceases to exist, particularly when its integrity is compromised with hybridization. The fact that threats to intra specific genetic diversity is not a mere abstraction, can be supplemented by the following phenomena -

a) Extinction- It is now known that disappearance of a species and local populations are primarily caused by habited alterations blocking of migratory routes along with pollution and other anthropogenic activities. All available information, including projected figures concerning human population growth indicate a persistence and accelerating threat to natural habitat. Though habitat destruction is a physically visible threat, ecological modification resulted from introduction of exotics and associated disease also play a crucial role in extinction.

b) Hybridization- Another major category that does not necessarily imply that loss of individual genes, but alters or modify the previous gene arrangements, which cannot be rebounded, may result in breakdown of adaptation to particular environment (Hinder, et al. [4]). As hybridization, due to genetic flexibility, is comparatively easier in fishes than other vertebrates, so the risk for the loss of integrity is more specially in the context of transplantation.

c) Hybridization, especially at intra specific level, creates an increasing threat to genetic integrity of local populations of several species. These threats are associated with ranching, intentional stocking and escape from net-pen rearing (Ryman and Utter, [1]; Allendrop and Leary, 1988; Hinder, et al. [4]; Waples, 1991a). Now a day, these phenomena drastically affect the genetic diversity of the prized fishes of India i.e. Rohu, Catla and Mrigal and is indicated by the significant fall in the harvest of 
these worthy species from major rivers of India (N.R. Chatterjee, 2015) The fish raised in farms through captive breeding, also contribute a threat to the native species, on their entry into native habitat through various mechanism. Specific guidelines, as to the extent of hybridization and on maximum allowable gene flow between donor and recipient to the degree of genetic divergence between them, should be implemented to conserve the unique native gene bank at its source.

\section{d) Genetic losses, within population}

Reductionorlossingeneticvariability is theadded contribution of a series of genetic phenomena which includes selection both intentional and unintentional, inbreeding and genetic drift following reduction in population size. Selection occurs when a particular genotype, by being more responsive to available and altered environmental stimuli, contribute proportionately more offspring than others. Such disproportionate favor led to the decrease of less favored species and ultimately results in loss of genetic diversity. As a process, apparently, it is very difficult to identify the very existence, nature, intensity and direction of selective force in a particular environment. But the differential activities of man such as selective harvest, domestication, breeding and intentional directional selection for production of specific species are good example of the existence of apparent selection (Hynes, et al. [5]).

The magnitude of loss in genetic variability results primarily from the reduction in heterozygosity, frequency of polymorphic loci i.e. average number of alleles per locus. Until now very few attentions have been focused on the effects of restricted population size. As we know heterozygosity of a population is mainly based on the relationship triangle $\Delta \mathrm{H}=1 / 2 \mathrm{Ne}$; Where Triangle $\mathrm{H}$ stands for decrease in heterozygosity per generation (equivalent to generational increase in inbreeding), when $\mathrm{Ne}$ is the genetically effective population size. $\mathrm{Ne}$, considerably less than that of the actual population size, is determined by sex ratio and the variance in family size. Long term determination of $\mathrm{Ne}$ is done by geometrical mean of Ne over generations and is therefore closer to the smallest Ne encountered over a series of generations than to the largest on (Ryman, et al. 1995). Thus, loss of genetic heterozygosity through small $\mathrm{Ne}$ in one generation may not be compensated by a correspondingly larger Nein subsequent generations. To avoid serious genetic loss within population over various period of time, minimum effective population size would be $50-100$ per generation (Lande and Barrowclough, [7]; Allendrop and Ryman, [1]).

It is now a realized fact that any activity that leads to the long or short-term depletion of effective population size below a critical level threatens the maintenance of genetic variability within population.

\section{Action needed to protect aquatic biodiversity-}

1) There is a need to bridge the existing gap between the societies of fishery biology and conservation biology.

2) An approach towards adopting and modifying traditionally used concepts, primarily used and applied within terrestrial conservationists.
3) These include establishment of minimum viable populations, identification of key stone or target species, designing of captive breeding programs for conservations of threatened taxa.

Considering the persistence and increasing threat, all involved participants (in capture and culture sector) should agree to the incompatibility of their actions with conservation approach. Finally, it must be accepted that the burden of proof relating to potential losses of any biodiversity move with the parties otherwise responsible for threatening the biodiversity. Now it is the responsibility of policy makers, administrator, Scientists and managers at all level of human interactions to formulate need based species-specific policies to serve and conserve the unique contribution of nature.

\section{References}

1. Allendorf FW, Ryman N, Utter F. Genetic management of hatchery stocks, Population genetics and fishery management. N. Ryman and F. Utter, editors. Washington Sea grants publication/ University of Washington Press, Seattle and London. 1987:141-159.

2. Andrews C. The conservation of fish by zoos and aquaria. B.L. Dresser, R.W. Reece and E. J. Maruska, editors. Proceedings from the 5th. World conference on breeding endangered species in captivity. Cincinnati, Ohio. 1988:9-20.

3. Chattopadhyay NR. Induced Fish Breeding. Oxford IBH, ISBN: 978-012-801774-6. 2016.

4. Hindar K, Ryman N, Utter F. Genetic effects of cultured fish on natural fish populations. Canadian Journal of Fisheries and Aquatic Sciences. 1991;48(5):945-957.

5. Hynes JD, Brown EH, Helle JH, Ryman N, Webster DA. Guidelines for the culture of fish stocks for resource management. Canadian Journal of Fisheries and Aquatic Sciences. 1981;38(12):1867-1876.

6. IUCN (International Union for Conservation of Nature and Natural Resources), The1997 IUCN red list of threatened animals, IUCN, Gland, Switzerland and Cambridge, U.K. 1997.

7. Lande R, Barrowclough GF. Effective Population Size, genetic variation and their use in population management. In M.E. Soule, editor, viable population for conservation. Cambridge University Press, Cambridge, England. 1987:87-124.

8. Philipp DP. Genetic implications of introducing Florida largemouth bass, Micropterus salmoides floridanus. Canadian Journal of fisheries and aquatic sciences. 1991;48(S1):58-65.

9. Ryman N, Utter F, Laikre L. Protection of aquatic biodiversity. 1987:1135.

10.Ray GC. Ecological diversity in coastal zones and Oceans. In EO Wilson and FM Peter, editors. Biodiversity, National Academy Press, Washington D.C. 1988:36-50.

11.Ryman N, Utter F. Population genetics and fishery management. Washington Sea grant program. Publications / University of Washington Press, Seatteland London.1987.

12.Ricker WE. Changes in the average size and average age of Pacific salmon. Canadian Journal of fisheries and aquatic sciences. 1981;38(12):1636-1656.

13.Ros T. Salmonids in the lake of Vanern area. 1981;34:21-32.

14.Ryman N. Conservation genetics consideration in fishery management. Journal of fish biology. 1991;39(sA):211-224. doi: 10.1111/j.10958649.1991.tb05085.x 